\title{
A prospective cross-sectional study to evaluate the economic burden of patients diagnosed with depression in a tertiary care hospital
}

\author{
D. K. Dhodi, S. R. Sinha*, F. Dawer, M. S. Chavan
}

Department of Pharmacology, Grant Government College and Sir JJ Group of Hospitals, Mumbai, Maharashtra, India

\author{
Received: 21 January 2020 \\ Revised: 11 March 2020 \\ Accepted: 12 March 2020 \\ *Correspondence: \\ Dr. S. R. Sinha, \\ Email: sinhashyamal@rediffmail.com
}

Copyright: (c) the author(s), publisher and licensee Medip Academy. This is an open-access article distributed under the terms of the Creative Commons Attribution Non-Commercial License, which permits unrestricted non-commercial use, distribution, and reproduction in any medium, provided the original work is properly cited.

\begin{abstract}
Background: The objective of the study was to evaluate the cost of care of depression in terms of direct and indirect costs.

Methods: 150 patients diagnosed with depression attending psychiatry OPD at Sir J.J. Group of Hospitals, Mumbai, fulfilling the inclusion criteria were explained about the study. Written informed consent were taken. Direct and Indirect costs were recorded in structured case record forms by interviewing the patients. Cost driving factors were identified.

Results: Total annual direct cost were INR 6,378.16 which included drug costs, travel expenses, physician's consultation, cost of investigations, hospitalisation cost while total Indirect costs were INR 16,860 which included days of work both of the patient and the caretaker.

Conclusions: The indirect cost was almost thrice the direct costs. Hospitalisation cost and loss of working days due to depression was contributed the most to the direct costs and indirect costs respectively. Economic burden of depression is found out to be $16.30 \%$ of per capita gross domestic product in year 2018-19.
\end{abstract}

Keywords: Depression, Economic burden, Direct and indirect cost

\section{INTRODUCTION}

Depression is a common mental disorder that is characterized by loss of interest or pleasure, feelings of guilt or low self-worth, disturbed sleep or appetite, low energy, and poor concentration, insomnia or hypersomnia, and occasionally suicidal thoughts..$^{1,2}$

In 2010, major depressive disorder (MDD) accounted for $2.5 \%$ (63.2 million) of DALYs worldwide. Between 1990 and 2010 , there was a $37 \%$ increase worldwide in the number of years of life lived with disability (YLDs) due to MDD (up from 46 million YLDs in 1990 to 63 million in 2010). ${ }^{3}$ The severity of MDD is associated with increased treatment costs, unemployment, and with reduced performance at work. ${ }^{4}$
The cost-of-treatment is an important issue while making informed choices about provision of psychiatric treatment services. ${ }^{5,6}$ When the resources are limited, it becomes incumbent upon health-care providers to ensure access to care to as many individuals as possible. Hence, there is a need to find the costs associated with various treatment options. However, health care costs can be computed in a variety of ways. ${ }^{7}$

Marked differences are present between developed and developing countries with respect to the structure of service provision, actual service utilization and the economic impact of psychiatric disorders. ${ }^{8-10}$ The studies about cost-of- treatment of psychiatric disorders are relatively fewer from India, an emerging and populous developing country. Further, Indian studies are lacking in 
estimating the economic burden of depression in urban population as they form the major bulk of burden of depression in India, we decided to conduct this study to evaluate the economic the cost of care of depression in terms of direct and indirect costs.

A prospective cross-sectional study to evaluate the economic burden of patients diagnosed with depression in a tertiary care hospital.

\section{METHODS}

\section{Study setting}

The study was conducted at grant government medical college and Sir JJ group of hospitals, Mumbai, India, which provides both inpatient and outpatient psychiatric services. Diagnosis of depression was made in accordance with ICD 10 after detailed assessment by the consultant. The hospital primarily caters to patients from lower socio-economic strata. There is a minimal consultation fee of INR 20 for seeking treatment at the centre. Regular follow-ups are advised as a part of treatment. The family members usually accompany the patients to the hospital. The study was conducted after obtaining permission from the institutional ethics committee.

\section{Patient characteristics}

The present study included outpatients and inpatients with an ICD 10 diagnosis of depression of more than 1year duration visiting psychiatry OPD (as the economic burden has been calculated on an annual basis) and started on Antidepressant. Patients above the age of 18 years of either gender were included in the study. Patients unable to respond to verbal questions and patients of depression also diagnosed with other medical or psychiatric conditions were excluded from the study. The participants were recruited after obtaining informed consent. The data collection was done between November 2018 to February 2019.

The data was obtained from the case record form filled by interviewing the patient's relatives about the basic demographic details, diagnosis, duration of illness and treatment, current treatment regimen, per-capita family income, and amount spent per-month on travel related to treatment. In cases of irregular family income, the participant was asked to provide an estimate of the average monthly income for the year.

\section{Cost estimation}

The cost calculations were done in Indian rupees (INR) per month, and rounded off to the nearest 10 (1 US Dollar was approximately equivalent to INR 70 at the time of the study). For the purposes of the study, the direct costof-treatment was sub-divided. The cost to patient included money spent on travel and medication purchased from outside the hospital if not available in the hospital pharmacy. Indirect costs as loss of working days per month, for working days lost- 5 days per week will be taken into account for both the patient and the care-taker.

\section{Statistical analysis}

The demographic and clinical characteristics of the patients were descriptively represented across the different diagnostic groups. The costs of treatment (both to direct and indirect) were calculated.

\section{RESULTS}

Economic evaluation of depression was done in two domains of direct and indirect cost by the means of various parameters of 150 participants, after obtaining permission from institutional ethics committee.

Demographic assessment depicted that females are more affected with depression than males.

On comparing the age, it was found that maximum females affected with depression falls in pre-menopausal group (41-50 years).

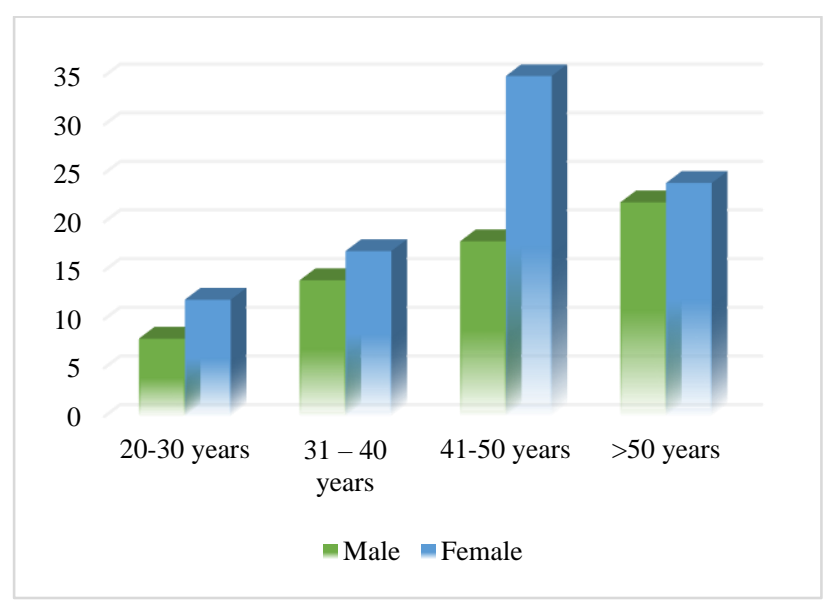

Figure 1: Age and gender distribution.

Males diagnosed with depression were maximum in the age group of $>50$ years (22), whereas females were maximum in the age group of 41-50 years (35).

\section{Assessment of direct and indirect cost}

Patients diagnosed with depression bear the burden of the disease by various parameter divided into two broad categories of direct and indirect costs. Direst cost amounts for $22.46 \%$ of the total disease burden by the patient. Cost of medication beard by the patient was less $(4.71 \%)$ as maximum drugs used to treat the depression are supplied by the hospital pharmacy free of cost.

One patient on an average has spent maximum amount on hospitalisation (6.73\%), psychotherapy sessions $(5.53 \%)$ 
and travelling $(5.31 \%)$ in direct cost expenditure. The detailed breakup of the direct cost burden can be easily understood in Figure 2.

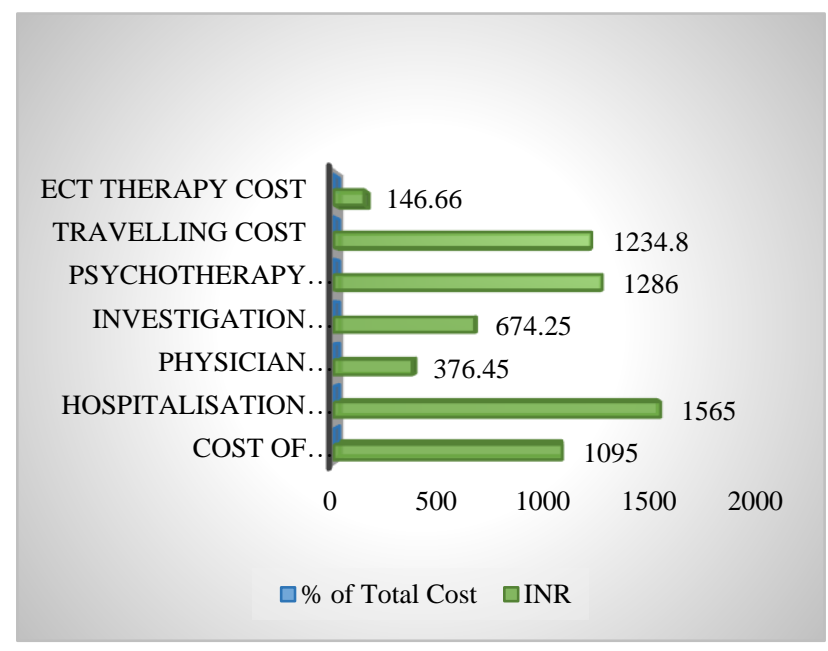

Figure 2: Distribution of direct cost spent on depression.

Maximum expenditure was on hospitalisation INR 1565 on average per person. Minimum expenditure was observed in ECT therapy INR 146.66.

Indirect cost beard by the patients were divided as income loss due to work days by the patient as well as the Caretaker. It was observed that the major burden of the disease was contributed by these factors, a total of $72.54 \%$.

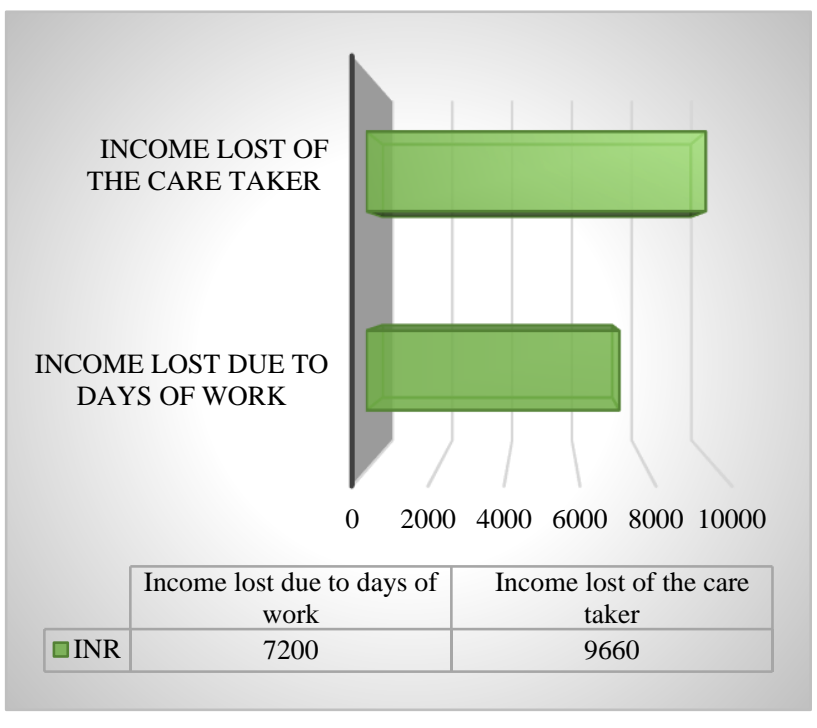

Figure 3: Distribution of indirect cost spent on depression.

Total annual direct cost was 6,378.16 INR while annual Indirect Cost was INR 16,860. Annual cost of Depression was 1NR 23,238.16/331.97 USD per patient. Total cost was $16.30 \%$ of per capita gross domestic product (GDP)
2018 among depression patients in India. The annual economic burden of depression in India is $1.2 \%$ of gross national product (GNP) of India.

\section{DISCUSSION}

Depression is a mental disorder with a high prevalence, particularly among women, Women suffering from depression were more than $50 \%$ in the total number of patients taken up for the study or findings co-related with study conducted by Bromet et al stated that women are twice as likely to have depression compared to males women are twice as likely to have depression compared to males, another study in Europe, Wittchen et al stating that disease has the highest prevalence among women aged 35 to 49 years which co-related with our study as the maximum women suffering from depression in our study was in age group of $41-50$ years $(n=35) .{ }^{11,12}$

Estimating the total cost burden using two different domains of direct and Indirect costs with the help of different parameters. Direct cost parameters being medication cost, hospitalisation cost, and physician cost similar parameters were used in various studies conducted in Europe reviewed by Karampampa et al. ${ }^{13} \mathrm{~A}$ Study by Luppa et al stated that the pharmacological treatment cost is also an important component of the total costs and was estimated to account for $6 \%$ to $29 \%$ of total direct health care costs whereas in our studies the total annual expenditure on medications was on $4.71 \%$ per patient as majority of drugs are provided free of cost to the patients from hospital pharmacy. ${ }^{14}$

Cost of medications are highly subjective variable as it depends upon the number of medicines and difference in cost of medicines. Hospitalisation cost accounts for 6.73 $\%$ of total cost and highest among direct cost parameters, which is co-related with the study conducted by Sarkar et al majority of cost expenditure and burden on per capita is due to hospitalisation leading to loss of work of the patient and the caretaker. ${ }^{15}$ Thus, Indirect costs were estimated in the domains of Income loss of the patient and of the caretaker it was found that indirect cost $(72.54$ $\%$ ) amounts three times the direct cost $27.46 \%$ co-related with the study conducted by Sobocki et al. ${ }^{16}$ Indirect costs account for more than half of the total burden of depression. Thus, the annual economic burden of depression in India is $1.2 \%$ of GNP of India which is highly variable across India and world due to the fluctuations in the cost of various parameters used as well as ever changing GDP/GNP every year.

\section{CONCLUSION}

To conclude, the present study suggests that the annual indirect cost was almost thrice the direct costs. Hospitalisation cost and loss of working days due to depression was contributed the most to the direct costs and indirect costs respectively. Economic burden of depression is found out to be $16.30 \%$ of per capita GDP 
in year 2018-19. Further studies may delve into the cost of treatment. The studies assessing cost of treatment in different settings nationally or internationally using similar methodology can help in a better comparative analysis.

\section{Strengths and limitations}

The findings of the study should be interpreted in the light of strengths and limitations. The strengths of the study include estimating not only the direct but considering the indirect cost. The study estimated the proportion of per-capita income of the patient being spent on treatment, in an attempt to understand the burden of treatment costs on the patient and the family. The study also estimated the total burden of depression on GDP/GNP of India.

The limitations of the study include purposive sampling leading to selection bias, reliance on self-report for income and travel expenses, and estimation of medication prices based upon rates quoted in drug indices. Disability benefits, if received were not factored into the calculations. The results reflect findings from one government teaching hospital and generalization is constrained by varied staffing patterns, hospital policies, and clientele in different institutions. The present study did not include costs of treatment of other comorbid disorders, and costs incurred on nutraceuticals. It was stratified by the socio-economic status, residence and other demographic characteristics, as data on these aspects could not be gathered accurately in the present set-up. Cost estimations may be carried in a variety of ways and the methods used in the present study represent one of the ways. Lack of similar Indian data for comparison.

\section{Funding: No funding sources}

Conflict of interest: None declared

Ethical approval: The study was approved by the Institutional Ethics Committee

\section{REFERENCES}

1. Depression: A Global Public Health Concern. WHO; 2012.

2. WHO. ICD-10. International Statistical Classification of Diseases and Related Health Problems 2010 - 10th Revision. Accessed on 30 September 2018.

3. Vos T. Years lived with disability (YLDs) for 1160 sequelae of 289 diseases and injuries 1990-2010: a systematic analysis for the Global Burden of Disease Study 2010. Lancet. 2013;380(9859):2163-96.

4. Birnbaum HG. Employer burden of mild, moderate, and severe major depressive disorder: mental health services utilization and costs, and work performance. Depress Anxiety. 2010;27(1):78-89.

5. Gustavsson A, Svensson M, Jacobi F, Allgulander C. Alonso J, Beghi E, et al. Cost of disorders of the brain in Europe 2010. Eur Neuropsychopharmacol. 2011;21:718-79.

6. Fineberg NA, Haddad PM, Carpenter L, Gannon B, Sharpe R, Young AH, et al. The size, burden and cost of disorders of the brain in the UK. J Psychopharmacol. 2013;27:761-70.

7. Akobundu E, Ju J, Blatt L, Mullins CD. Cost-ofillness studies: a review of current methods. Pharmaco Economics. 2006;24:869-90.

8. Sharma P, Das SK, Deshpande SN. An estimate of the monthly cost of two major mental disorders in an Indian metropolis. Indian J Psychiatry. 2006;48:1438 .

9. Somaiya M, Grover S, Avasthi A, Chakrabarti S. Changes in cost of treating schizophrenia: comparison of two studies done a decade apart. Psychiatry Res. 2014;215:547-53.

10. Sarkar S, Mathan K, Sakey S, Shaik S, Subramanian K, Kattimani S. Cost-of-treatment of clinically stable severe mental lilnesses in India. Indian $\mathbf{J}$ Soc Psychiatry. 2017;33:262-8.

11. Bromet E, Andrade LH, Hwang I, Sampson NA, Alonso J, de Girolamo G, et al. Cross-national epidemiology of DSM-IV major depressive episode. BMC Med. 2011;9:90.

12. Wittchen HU, Jacobi F. Size and burden of mental disorders in Europe: a critical review and appraisal of 27 studies. Eur Neuropsychopharmacol. 2005; 15:357-76.

13. Karampampa K, Borgstrom F, Jonsson B. Economic burden of depression of society. Medicographia. 2011;33(2):163-8.

14. Luppa M, Heinrich S, Angermeyer MC, Konig HH, Heller RSG. Cost-ofillness studies of depression: a systematic review. J Affect Disord. 2007;98:29-43.

15. Sarkar S, Mathan K, Sakey S, Shaik S, Subramanian K, Kattimani S. Cost-of-treatment of clinically stable severe mental lilnesses in India. Indian $\mathbf{J}$ of Social Psychiatry. 2017;33(3):262.

16. Sobocki P, Ekman M, Agren H, Runeson B, Jonsson B. The mission is remission: health economic consequences of achieving full remission with antidepressant treatment for depression. Int $\mathrm{J}$ Clin Pract. 2006;60:791-8.

Cite this article as: Dhodi DK, Sinha SR, Dawer F, Chavan MS. A prospective cross-sectional study to evaluate the economic burden of patients diagnosed with depression in a tertiary care hospital. Int J Basic Clin Pharmacol 2020;9:722-5. 